\title{
Poredu: um ambiente de programação em blocos
}

\author{
Lucas Abreu da Silva ${ }^{1,2}$, Esteic Janaina Batista ${ }^{1,2}$, Camila Leite da Silva ${ }^{1,2}$, \\ Anderson Corrêa de Lima ${ }^{1}$ \\ ${ }^{1}$ Universidade Federal de Mato Grosso do Sul campus Ponta Porã (UFMS/CPPP) \\ Ponta Porã - MS - Brasil \\ ${ }^{2}$ Bolsistas do Programa de Educação Tutorial - PET/SESu/MEC \\ \{lucasabreudasilva, esteicejanaina, camila.leite002, anderson.correa.lima\}@ gmail.com
}

\begin{abstract}
Resumo. O ensino de Programação vem sofrendo muitas alterações desde o surgimento das linguagens de programação. Com isso, para facilitar o processo de ensino-aprendizagem são necessárias novas técnicas que apresentam, em si, metodologias diferenciadas para dinamizar a atividade de programar. Sendo assim, este artigo apresenta uma plataforma de programação visual para crianças e adolescentes aprenderem a programar de forma mais simplificada e lúdica, trabalhando intrinsecamente com o pensamento computacional, lógica e matemática.
\end{abstract}

\section{Cenário de Uso}

São muitas as pesquisas realizadas sobre o tema das novas habilidades humanas requeridas, para a inserção na rotina urbana e diária deste século. Dentre estas habilidades destaca-se a fluência tecnológica. Hoje em dia os indivíduos não são apenas consumidores de novas tecnologias, mas também podem atuar como agentes participativos e autores destas [Demo 2008]. Outras habilidades requeridas neste século são conhecidas como habilidades transversais e multidisciplinares, são elas: a comunicação, a colaboração, a criatividade e o pensamento crítico [Porvir 2015]. Tais habilidades são imprescindíveis quando trabalha-se com ferramentas de programação nas escolas. Estas habilidades acabam desempenhando um papel importante no auxílio do pensamento computacional. Esta forma de pensamento é característica dos cientistas da computação, mas é universalmente aplicável, ela envolve um conjunto de atitudes e habilidades tais como o uso da recursividade, da abstração e da decomposição na solução de problemas tanto técnico-científicos quanto da vida cotidiana [Wing 2006].

O pensamento computacional geralmente é incentivado em estudantes de cursos do eixo de computação na graduação por meio da criação de programas utilizando linguagens de programação diversas, a maioria delas de alto nível. No entanto, em sua maior parte, as linguagens de programação disponíveis são bastante complexas para o público infantil. Além disto, visualmente elas não são atrativas.

Na busca de solucionar estes problemas, particularmente no âmbito educacional, algumas ferramentas de programação em blocos têm sido desenvolvidas com este propósito, pois facilita o ensinamento e a compreensão de códigos, criar jogos e aplicativos. Uma das ferramentas mais populares para ensino de programação para criança é o Scratch, desenvolvido qu MIT (Massachusetts Institute of Technology), e utiliza unoma linguagem 
de programação visual em blocos. A linguagem Scratch permite que o estudante desenvolva seus próprios jogos, animações e histórias. O Scratch é uma ferramenta baseada na linguagem LOGO desenvolvida pelo pesquisador Seymour Papert e sua equipe.

Papert, denominou a teoria do construtivismo, que descreve que o indivíduo, por meio do computador, pode construir seu próprio conhecimento e isso resulta, direta ou indiretamente, na produção de algo, que pode ser um jogo, um programa, um website ou um poema, por exemplo. Segundo Papert a construção do conhecimento dá-se em duas vertentes: a primeira é quando o indivíduo cria um objeto no computador e a segunda é quando ele cria algo do seu interesse pessoal, sentindo-se mais motivado. Essa motivação é fundamental, uma vez que, para Papert, o envolvimento afetivo torna a aprendizagem mais efetiva [Resnick et al. 1988].

Este trabalho apresenta uma nova ferramenta de programação visual em blocos denominada Poredu, que desafia o usuário a mover o personagem até um objetivo, utilizando blocos de programação. O objetivo da ferramenta é ensinar comandos básicos de programação, tais como: sequência, condições e laços de repetição. A ferramenta é destinada para crianças com idade a partir de oito anos, ela pode ser utilizada nas escolas, principalmente em projetos de programação e robótica.

Este trabalho está estruturado da seguinte forma: a Seção 2 apresenta o contexto e as ferramentas do desenvolvimento do Poredu, a Seção 3 apresenta a ferramenta, a Seção 4 uma discussão da avaliação do Poredu e a Seção 5 as considerações finais ressaltando o diferencial do Poredu em relação à algumas ferramentas similares.

\section{Desenvolvimento}

Anualmente na cidade de Ponta Porã, no estado de Mato Grosso do Sul, é realizado um evento de robótica intitulado "Robo Ára". Ára é uma palavra em guarani que significa dia, logo "Robo Ára"é o Dia do Robô. O nome foi escolhido devido ao aspecto cultural e fronteiriço da cidade que faz fronteira seca com o Paraguai.

O evento "Robo Ára"tem os seguintes objetivos: 1) Prestigiar os alunos que obtiveram medalhas e faixas na Olimpíada Brasileira de Robótica (OBR) no ano anterior à realização do evento. 2) Promover o contato das crianças do ensino básico com a robótica por meio de demonstrações e atividades específicas para cada nível. 3) Incentivar os alunos do município a participarem da prova prática da OBR. 4) Permitir a troca de experiências entre os acadêmicos da comissão organizadora. A comissão é formada por professores, técnicos administrativos da unidade e estudantes de todos os cursos da universidade, incluindo os cursos da área de tecnologia e licenciatura [Batista et al. 2017].

O logotipo do evento (Figura 1) é baseado no bloco do kit LEGO NXT, bastante utilizado em escolas. Ele possui cores com significados locais e em uma das mãos segura uma guampa de tereré, que é uma bebida típica da região. Um escultura no formato de guampa também está localizada na entrada do município onde esta ação é realizada.

Como a maioria do público do evento é infantil, para que também houvessem momentos de confraternização e brincadeiras com as crianças decidiu-se criar um mascote real. O mascote foi nomeado como Porãnito (Figura 2) e segue os mesmos padrões de cores e formatos do logotipo. Nas primeiras edições do evento, nos anos de 2015 e 2016, a presença do mascote gerou momentos bastante lúdicos e festivos. 
VI Congresso Brasileiro de Informática na Educação (CBIE 2017)

Anais dos Workshops do VI Congresso Brasileiro de Informática na Educação (WCBIE 2017)

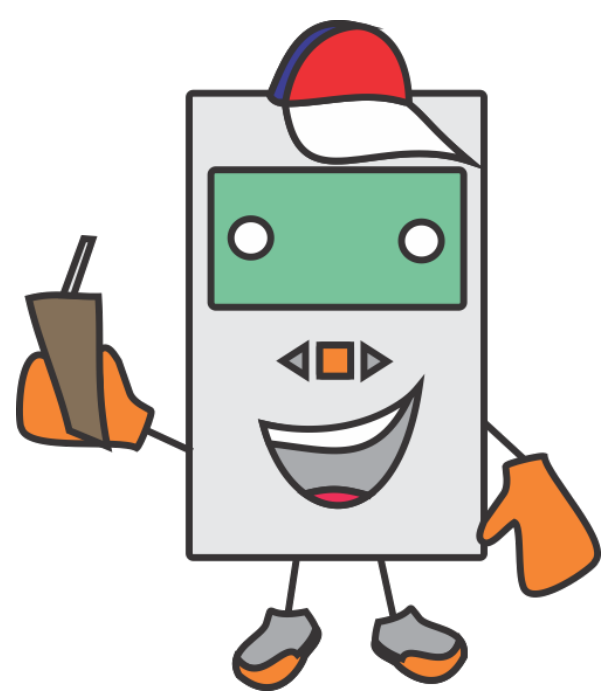

Figura 1. Logotipo do Robo Ára

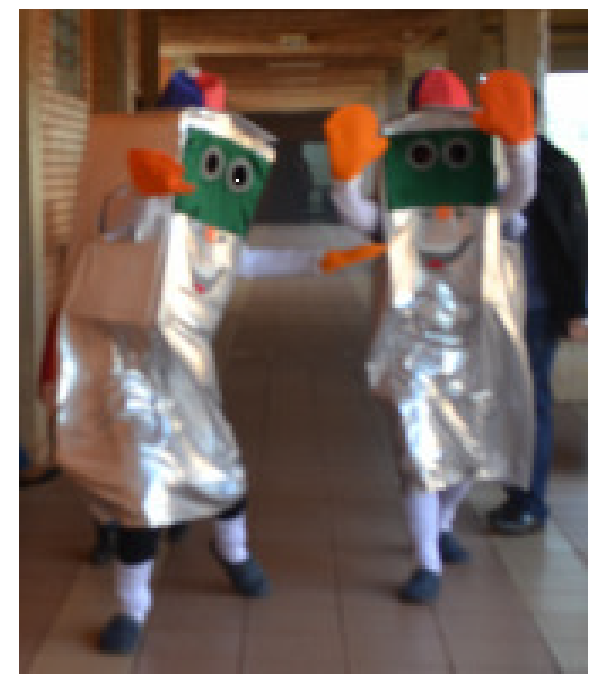

Figura 2. Mascotes do Evento

Durante a segunda edição do evento, decidiu-se promover o uso da computação desplugada. A computação desplugada é uma alternativa para a execução de atividades que estimulam o raciocínio computacional sem o uso de computadores ou quaisquer outros recursos eletroeletrônicos [Ferreira et al. 2015]. Foi realizado um teatro intitulado: "Teatro dos Porãnitos". Para a peça de teatro foram confeccionados em papelão comandos de programação para o Porãnito, tais como: "andar", "polichinelo", "flexão", "repita" e "pular".

O enredo da peça consistia de uma história onde um professor português, que representava o engenheiro do Porãnito, pedia ajuda para a plateia para programá-lo novamente durante a encenação. Os comandos foram afixados em um mural, que simulava um ambiente de programação. Foram produzidos efeitos sonoros para a peça com voz de robô. O Porãnito deveria durante a peça "executar"os comandos selecionados pela plateia na sequência respeitando as condições e laços de repetição. 
VI Congresso Brasileiro de Informática na Educação (CBIE 2017)

Anais dos Workshops do VI Congresso Brasileiro de Informática na Educação (WCBIE 2017)

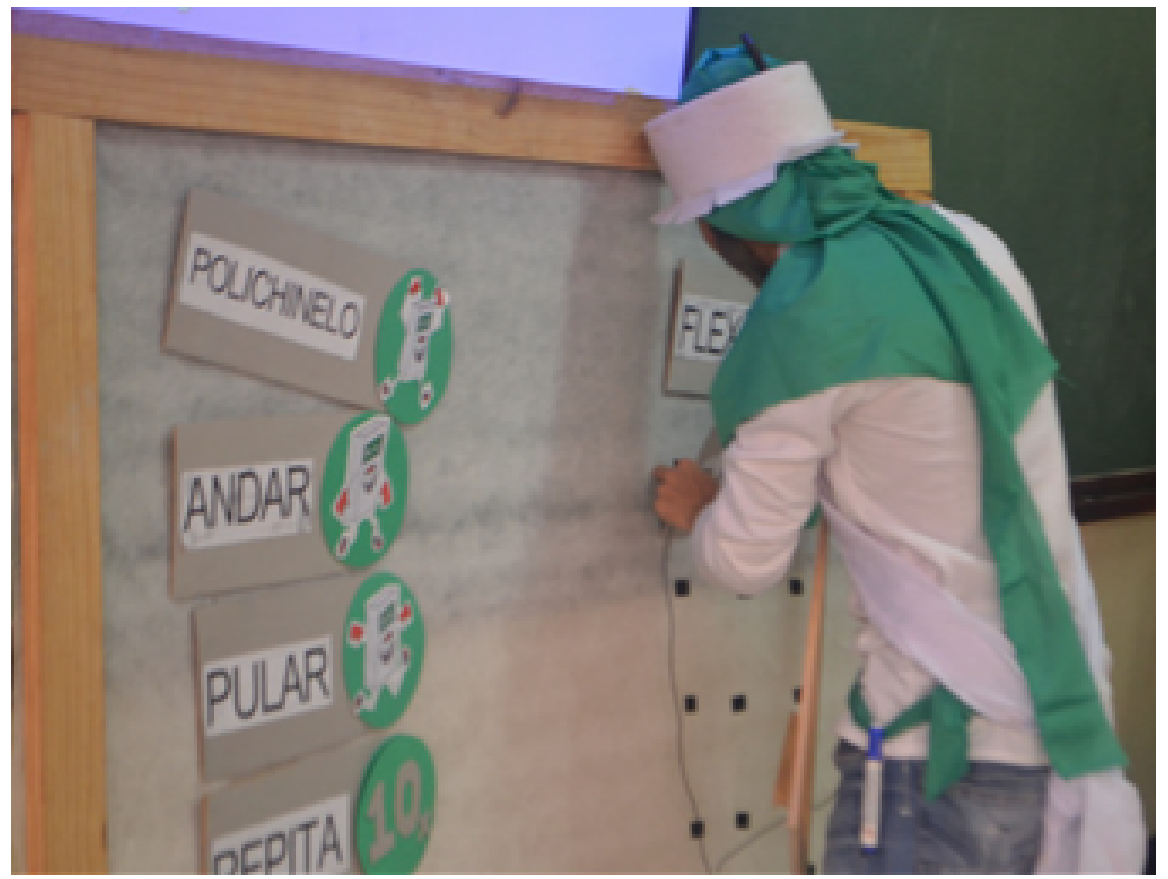

Figura 3. Teatro do Porãnito

Ações como a criação de um logo e a realização do teatro motivaram o desenvolvimento de um ambiente de programação visual em blocos, no qual o personagem fosse o logotipo do evento, o Porãnito. Este ambiente de programação foi denominado Poredu. O nome escolhido enfatiza o contexto regional e facilita a utilização do ambiente em futuras edições do evento Robo Ára.

O ambiente foi desenvolvido utilizando a biblioteca da Google Blockly, pois facilita o desenvolvimento de linguagens visuais para ambientes web e mobile, que tem sido utilizadas em ferramentas como: o AppInventor, que permite o desenvolvimento de aplicativos para Android com acesso a banco de dados, além de prover funções de comunicação com kits de robótica e de prototipagem por meio da programação em blocos [Finizola et al. 2014].

A plataforma apoia as práticas Open Source, desta forma o website correspondente e os respectivos códigos estão disponíveis em um endereço web do github ${ }^{1}$.

\section{Apresentação do software}

O Poredu possui diversas fases com diferentes desafios que promovem o ensino de conceitos de programação. No início de cada fase é apresentado um vídeo que aborda os seguintes temas: 1) Conceitos que podem ser utilizados para completar as tarefas da fase. 2) Um objetivo no qual o usuário deverá utilizar programação para completar a fase. 3) Dicas de comandos de fases anteriores. A Figura 4 ilustra uma tela do vídeo.

Os principais elementos que compõem o ambiente Poredu são a área de programação em blocos e o simulador. A Figura 5 apresenta a visão geral da plataforma, onde o usuário pode interagir e programar o Porãnito.

\footnotetext{
${ }^{1} \mathrm{O}$ código do Poredu está disponível no seguinte endereço: luca sabreus . github . com/poredu.
} 
VI Congresso Brasileiro de Informática na Educação (CBIE 2017)

Anais dos Workshops do VI Congresso Brasileiro de Informática na Educação (WCBIE 2017)

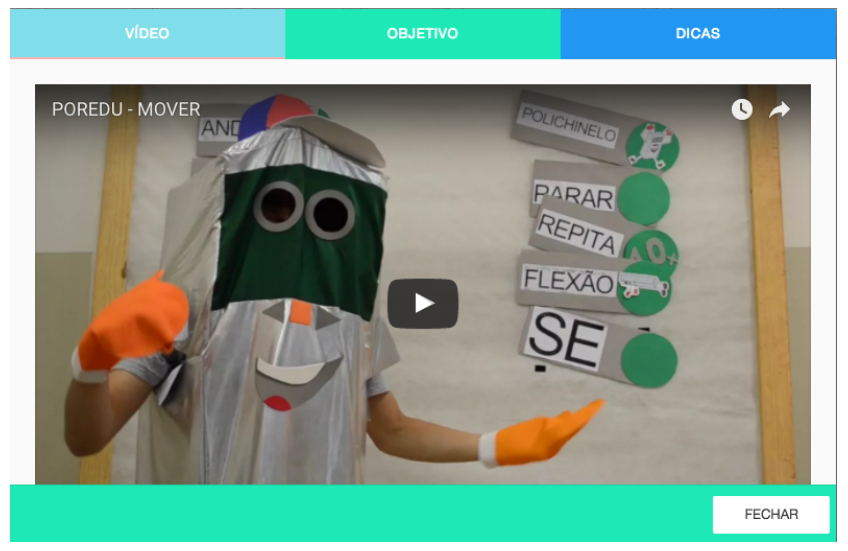

Figura 4. Aviso mostrando o vídeo, objetivo e dicas da fase

\section{PREDU}

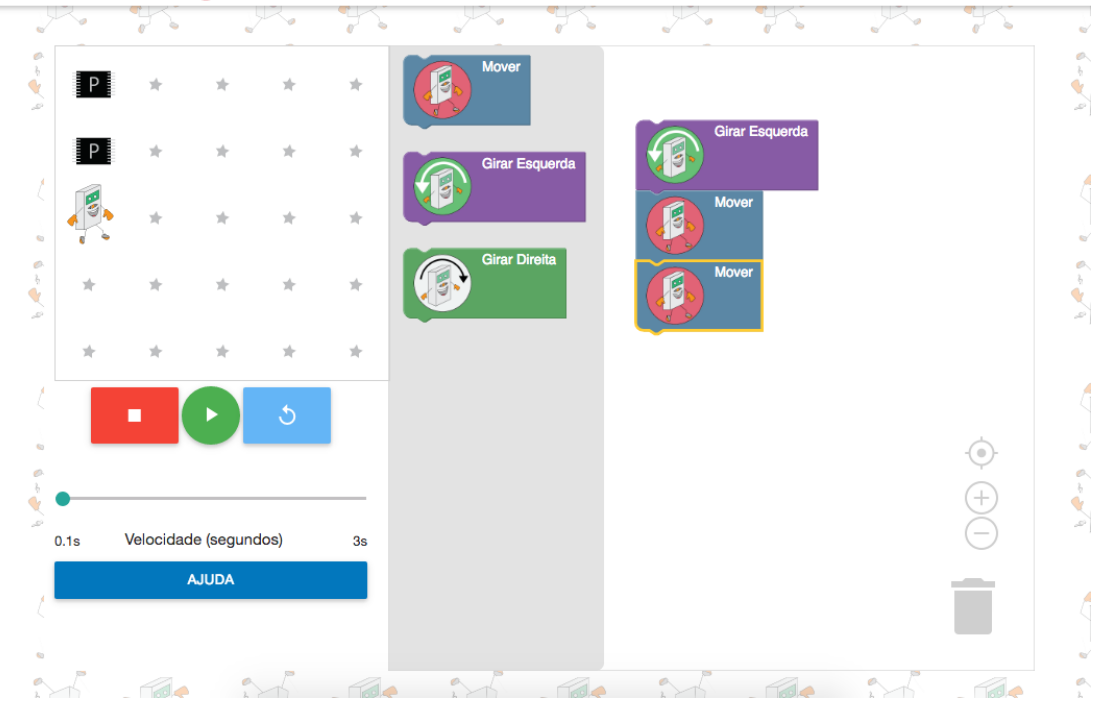

Figura 5. Visão Geral da plataforma

\section{1. Área de Trabalho por Blocos}

O ambiente de programação em blocos representada pela Figura 6 é composto de três partes: a primeira é área de execução, a segunda é a paleta de comandos e a terceira é a área de programação.

Em cada fase, dependendo do nível, são disponibilizados somente os blocos que serão necessários para completar o objetivo da fase. A delimitação de blocos estimula e facilita a assimilação do conteúdo do desafio da fase. A medida que o usuário vai assimilando os conceitos básicos de programação, novos desafios lógicos vão sendo disponibilizados. Um exemplo é o caso onde a fase não apresenta o comando "Girar Direita", desta forma o usuário necessita utilizar três vezes o comando "Girar Esquerda" para ter o mesmo resultado.

As fases do Poredu utilizam até sete blocos de comandos. São eles: "Mover", "Girar Esquerda", "Girar Direita", "Repetir", "Mudar Personagem", "Porãnito" e "Zygmundi". O ambiente de programação permite ao usuário inserir, mover, excluir e trocar 
VI Congresso Brasileiro de Informática na Educação (CBIE 2017)

Anais dos Workshops do VI Congresso Brasileiro de Informática na Educação (WCBIE 2017)

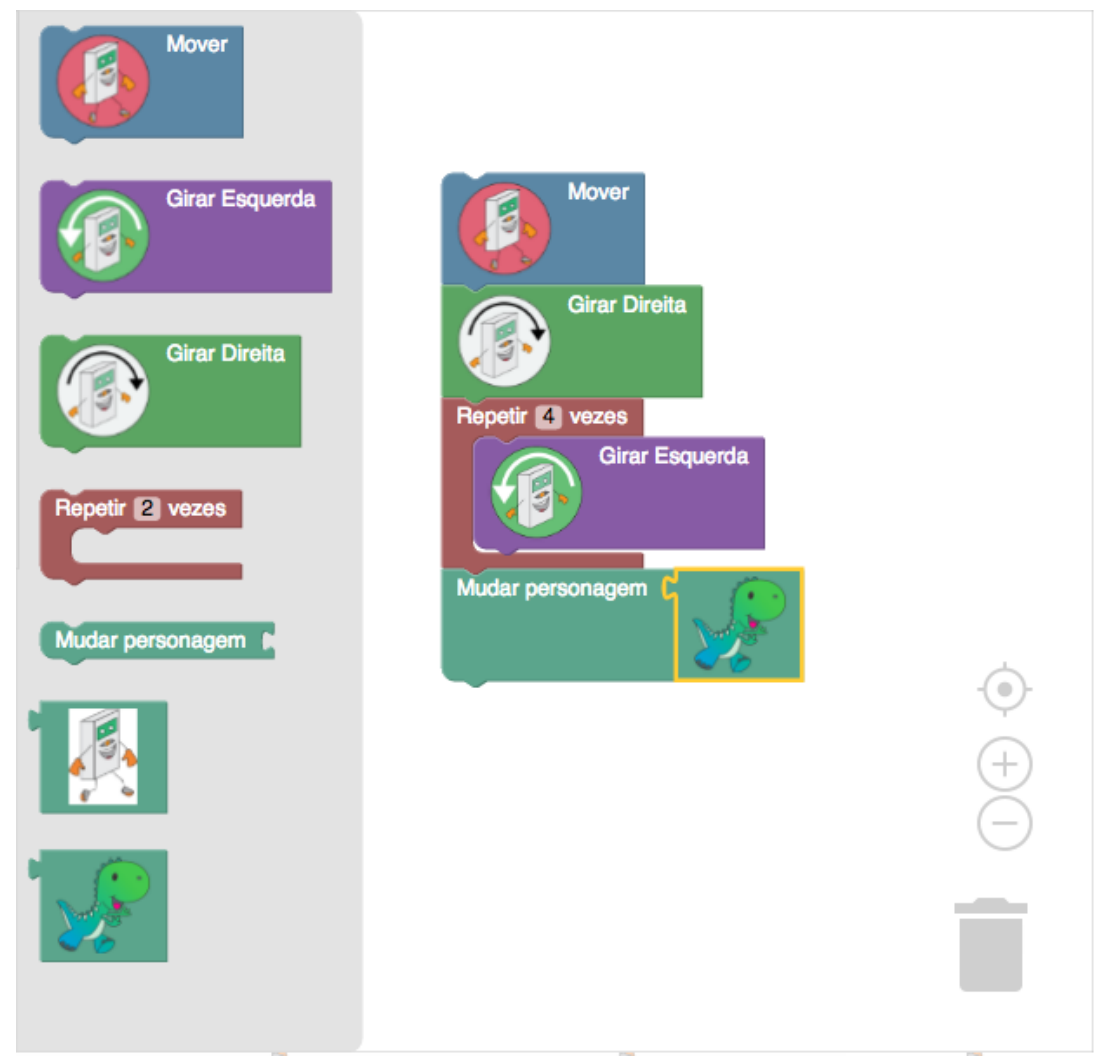

Figura 6. Área de Trabalho por blocos

os blocos de ordem. A Figura 7 representa os blocos de comandos disponíveis.

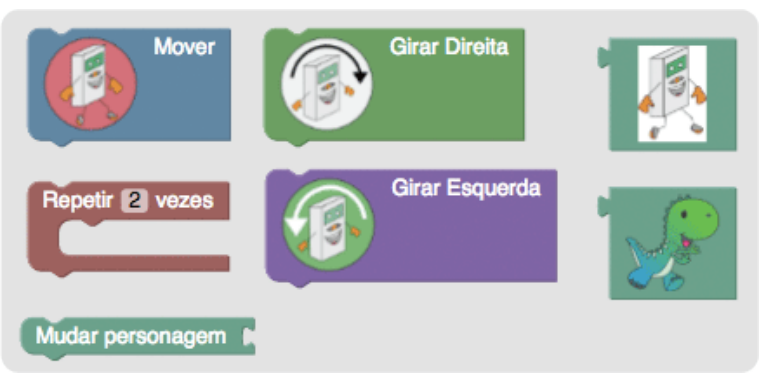

Figura 7. Conjunto de Blocos

\subsection{Simulador}

O simulador é ambiente no qual o usuário conseguirá visualizar o personagem Porãnito (Robô) e colocar em prática o código que foi criado. O simulador possui botões com os quais o usuário pode interagir, nele o usuário pode observar o feedback do trecho de programação criado. Observar este retorno estimula e facilita a aprendizagem A figura Figura 8 representa o simulador do Porãnito. O simulador apresenta botões para as seguintes funções:

- Parar: Interrompe a execução do simulador e deixa o personagem na última posição alcançada. 
VI Congresso Brasileiro de Informática na Educação (CBIE 2017)

Anais dos Workshops do VI Congresso Brasileiro de Informática na Educação (WCBIE 2017)

- Executar: Quando este botão é pressionado o código da Área de Trabalho por blocos é convertido em comandos visuais que o personagem irá executar sincronamente.

- Resetar: Quando este botão é pressionado é realizada uma pausa na execução e o personagem retorna para a posição inicial da fase.

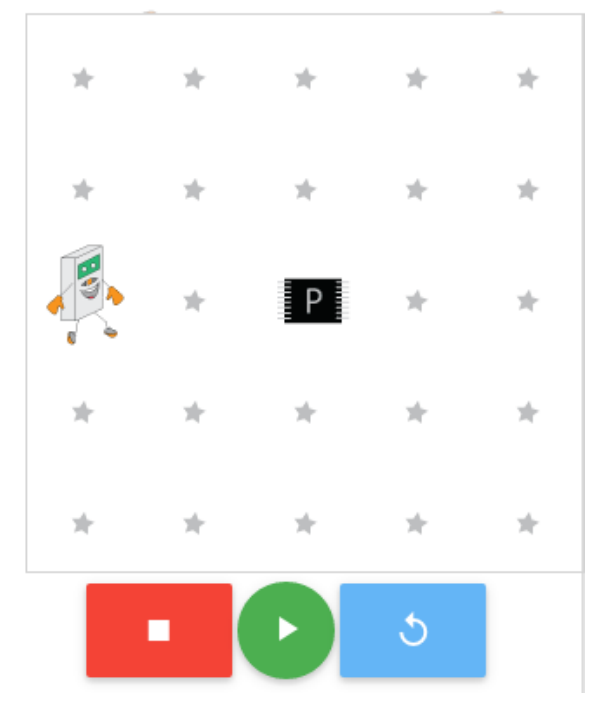

Figura 8. Simulador

\section{Avaliação}

O jogo foi avaliado por crianças de 10 a 12 anos, que participam de aulas de robótica na escola e que já haviam feito uso das ferramentas do Code.org. Aplicou-se um questionário sobre a ferramenta, em que utilizou-se as heurísticas simplificadas e adaptadas para crianças utilizando a escala Likert por meio de Smileys. As heurísticas de Nielsen foram utilizadas para identificar problemas de usabilidade em uma interface de usuário; e as heurísticas de Malone para avaliar o divertimento proporcionado por uma interface com o usuário. As heurísticas foram escolhidas por ter apresentado bons resultados, como no trabalho de [Valente 2011]. Por meio dos testes as crianças apontaram algumas carências na ferramenta como: a falta de uma barra de progresso, informando em qual passo da fase se encontram, e também a falta de permitir que eles resolvessem o desafio de outras maneiras, quando eles alcançavam o objetivo utilizando outra sequência de blocos.

\section{Considerações finais}

O raciocínio lógico não pode ser visto, apenas, como mecanismo de reconhecimento matemático. Assim sendo, a disciplina de programação não pode, de maneira alguma, limitar-se ao uso computacional. É preciso ir além: fazer a criança reconhecer a programação como utilidade social, principalmente nas suas relações cotidianas. Este trabalho apresentou uma nova ferramenta visual para o ensino de programação de computadores. A ferramenta é denominada Poredu, com ela é possível ensinar a programação, incentivando o ensino de comandos básicos de uma forma gráfica, colorida e lúdica.

É importante, ressaltar, que apesar do Poredu apresentar uma linguagem de programação visual, como nas populares ferramentas Scratch e AppInventor, ele tem um 
VI Congresso Brasileiro de Informática na Educação (CBIE 2017)

Anais dos Workshops do VI Congresso Brasileiro de Informática na Educação (WCBIE 2017)

objetivo diferente. Pois estas ferramentas tem como objetivo que a criança construa um jogo ou aplicativo utilizando a linguagem visual em blocos, enquanto que o Poredu fornece um desafio à crianças, e este deve ser realizado, utilizando os blocos de programação apresentados.

Há diversas ferramentas, com o mesmo objetivo do Poredu, encontrados no portal Code.org ${ }^{2}$. No entanto, os vídeos de explicação dos blocos são em inglês, o que dificulta o aprendizado de crianças que não conhecem o idioma. Já o Poredu, utiliza o português, além de fazer uso de elementos de um evento, já disseminado para o público da cidade de Ponta Porã e região.

Uma nova versão da ferramentas está sendo desenvolvida com base nas carências levantadas na avaliação realizada pelas crianças, podendo assim, realizar novos testes com um grupo maior de usuário.

\section{Referências}

Batista, E. J. S., da Silva, L. A., da Silva, C. L., de Araújo Santos, Q., and de Castro Júnior, A. A. (2017). Evento temático como forma de disseminação e desmistificação da robótica. Anais do Computer on the Beach, pages 297-306.

Demo, P. (2008). Habilidades do século xxi. Boletim Técnico do SENAC, 34(2):4-15.

Ferreira, A. C., Melhor, A., Barreto, J., de Paiva, L. F., and Matos, E. (2015). Experiência prática interdisciplinar do raciocínio computacional em atividades de computação desplugada na educação básica. In Anais do Workshop de Informática na Escola, volume 21, page 256.

Finizola, A. B., Raposo, E. H. S., Pereira, M. B. P. N., Gomes, W. S., de Araújo, A. L. S. O., and Souza, F. V. C. (2014). O ensino de programação para dispositivos móveis utilizando o mit-app inventor com alunos do ensino médio. In Anais do Workshop de Informática na Escola, volume 20, page 337.

Porvir (2015). Competências para o século 21. Accesso em: 17 mar. 2017.

Resnick, M., Ocko, S., and Papert, S. (1988). Lego, logo, and design. Children's Environments Quarterly, pages 14-18.

Valente, J. F. P. (2011). Avaliação da usabilidade e diversão em interfaces web para criançascaso de estudo escolinhas. pt. Mestrado Integrado em Engenharia Informática e Computação Tese de Mestrado Integrado em Engenharia Informática e Computação), Universidade do Porto, Faculdade de Engenharia.

Wing, J. M. (2006). Computational thinking. Communications of the ACM, 49(3):33-35.

\footnotetext{
${ }^{2} \mathrm{O}$ site Code.Org tem o objetivo de ensinar os conceitos básicos da Ciência da Computação, principalmente da programação, por meio de diversas ferramentas e cursos gratuitos para todas as faixas etárias.
} 